\title{
Topic Study Group No. 29: Mathematics and Creativity
}

\author{
Demetra Pitta-Pantazi, Dace Kūma, Alex Friedlander, \\ Thorsten Fritzlar and Emiliya Velikova
}

\section{The Programme}

The aim of TSG 29, Mathematics and Creativity, was to bring together mathematics educators, educational researchers, mathematics teachers, and curriculum developers for the international exchange of experiences and ideas related to mathematical creativity. Approximately 50 researchers from 20 countries participated. Eleven articles, seven short oral communications, and one poster were presented during the conference. Participants were given the opportunity to present their work and discuss important aspects of mathematical creativity. The TSG was organised in four sessions with article presentations and two sessions with short oral presentations. The main topics that the TSG addressed were:

1. Definition and measurement of mathematical creativity

2. Tasks, methods, and environments that have the potential to promote mathematical creativity

3. Problem posing and mathematical creativity.

Co-chairs: Demetra Pitta-Pantazi, Dace Kūma.

Team members: Alex Friedlander, Thorsten Fritzlar, Emiliya Velikova.

D. Pitta-Pantazi $(\bowtie)$

University of Cyprus, Nicosia, Cyprus

e-mail: dpitta@ucy.ac.cy

D. Kūma

Liepaja University, Liepāja, Latvia

e-mail: dace.kuma@liepu.lv

(C) The Author(s) 2017 


\section{Session 1: Definition and Measurement of Mathematical Creativity}

The activities of the TSG started with the co-chairs and team members of the TSG offering a brief overview of the main topics that the group would address. During the first session, three articles were presented. The first two presentations proposed two new tools and methods for the measurement of mathematical creativity. In their article "Creativity-in-progress rubric on proving: Enhancing students creativity," Karakok, El Turkey, Savic, Tang, Naccarato, and Plaxco presented a new formative assessment tool, the Creativity-in-Progress, which can be used to measure individuals' creativity while engaged in mathematical proof. The researchers described the development of this tool and its categories. Joklitschke, Rott, and Schindler, in their article "Revisiting the identification of mathematical creativity: Validity concerns regarding the correctness of solutions," suggested that with the existing methods for the measurement of creativity, students' potential is not sufficiently assessed and valued. Thus, they suggested modifications. One of the modifications they suggested was that students' erroneous or unfinished solutions may also be used for the assessment of mathematical creativity. A third study presented during the first session by Pitta-Pantazi and Sophocleous, entitled "Higher order thinking in mathematics: A theoretical formulation and its empirical validation," went beyond to the identification and measurement of mathematical creativity and extended towards the assessment and measurement of higher order thinking in mathematics. The researchers suggested that higher order thinking is constituted by several subcomponents: basic, critical, and complex mathematical thinking. In their article, the researchers empirically validated a model of higher order thinking and presented tools that they used for its measurement.

\section{Session 2: Tasks, Methods, and Environments that Have the Potential to Promote Mathematical Creativity}

In the second session, the articles presented addressed types of tasks, methods, and environments that have the potential to promote students' mathematical creativity. Mathematics educators and researchers presented types of activities as well as qualitative and quantitative data from students' work.

In their presentation "Developing flexibility of problem solving strategies in the classroom," Jesenska and Semanišinová suggested competitions in problem solving for groups of students as a method that could potentially promote students' mathematical creativity. In these competitions, students are prompted to find innovative solutions to given problems. The researchers offered five such problems and corresponding strategies exhibited by their students. In his presentation "Some types of creativity-promoting tasks," Alex Friedlander classified and described various types of tasks that have the potential to promote students' mathematical creativity. He suggested that creativity-promoting tasks may involve some or all of 
the following actions: planning, implementation of a plan, revision, invention of a new procedure, reflection, and production of new knowledge.

\section{Session 3: Tasks, Methods, and Environments that Have the Potential to Promote Mathematical Creativity}

During the third session, researchers continued the discussion on tasks, methods, and environments that may be used to develop mathematical creativity. In their presentation of the article "Ornaments and tessellations: encouraging creativity in the mathematics classroom," Moraová and Novotná presented a number of teaching experiments from the $\mathrm{M}^{3} \mathrm{EaL}$ project (Multiculturalism, Migration, Mathematics Education, and Language), which aimed at the development of mathematical creativity in migrant pupils and pupils of different sociocultural backgrounds. They found that when teachers are faced with a cultural heterogeneity in their classrooms and they cannot rely on the traditional textbooks, they tend to become more creative in their planning of the lessons and in some cases this also encourages their students' creativity. El-Sahili, Al-Sharif, and Khanafer investigated mathematical creativity in secondary education. In their article "Mathematical creativity: The unexpected links," they suggested that secondary school students can solve mathematical problems in a non-traditional manner that requires the formation of hidden bridges between different mathematical domains or ideas that at first glance appear unrelated. They suggested that this ability is not restricted only to professional mathematicians or postgraduate mathematics students but that students at the intermediate and secondary school level can also possess it. Assmus and Fritzlar focused on mathematical creativity in primary school and more specifically on primary school students' inventions processes. In their article "Mathematical creativity in primary school," Assmus and Fritzlar also argued that primary school gifted students not only can solve and pose problems but are also able to purposefully or freely create new mathematical objects. The researchers offered examples of such invention processes.

\section{Session 4: Problem Posing and Mathematical Creativity}

The topic of the last session was problem posing and mathematical creativity. In this session, three articles were presented. In particular, in his presentation of the article "Remarks on creative posing of problems: Pro et contra," Kasuba discussed the creative posing and design of mathematical problems and what specifically should be included in the formulation of a problem. Sophocleous, in her article "Mathematical problem-posing ability and critical thinking in mathematics," investigated the relationship between primary school students' problem-posing ability and their critical thinking in mathematics. In their presentation of the article "Flexibility of pre-services' teachers in problem posing in different environments," Daher and Anabousy presented the results of the impact of four different environments that aimed at promoting 
pre-service teachers' flexibility in posing problems. The four different environments were: (1) with technology and with a "what if not" strategy, (2) with technology but without "what if not" strategy, (3) without technology but with a "what if not" strategy, and (4) one without technology and without a "what if not" strategy.

\section{Two Sessions with Short Oral Communications}

Two sessions were devoted to short oral communications. Primarily, researchers concentrated on tasks and methods that may promote mathematical creativity and ability in and out of school. Regarding school mathematics, Ferrington proposed that creativity can be developed by asking challenging questions, while Tanaka suggested that asking students to pose problems can be seen as a creative activity. Vilches and Gorriz suggested that open challenges encourage students to create their own innovative product. Furthermore, Mamiy and Mamiy focused on the mathematical circle as a means for developing mathematical creativity. Furthermore, Bártlová claimed that teachers can develop students' mathematical abilities out of school by encouraging students to participate in unconventional environments such as interactive science centres. Moreover, Mikaelian presented an approach to aesthetic education in learning mathematics, while Abdounur highlighted the way in which the relationship between mathematics and theoretical music influenced our understanding of important mathematical concepts. Finally, one poster presented by Choe provided insights into South Korea's education system and its negative impact on students' mathematical creativity.

In the closing session of the TSG, researchers raised questions which are crucial and open to further investigation. They also offered ideas for future research studies and collaborations. Overall, the work of the TSG demonstrated how much research in mathematics creativity has evolved and still how many questions need to be answered. It appears that mathematical creativity is an important topic within the field of mathematics education that is worth pursing and has a lot to offer in our highly demanding and rapidly changing world.

Open Access Except where otherwise noted, this chapter is licensed under a Creative Commons Attribution 4.0 International License. To view a copy of this license, visit http://creativecommons. org/licenses/by/4.0/.

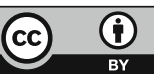

